\title{
Green-switch: reducing the conflict between the industrial and the residential interface
}

\author{
A. Sharma \\ School of Architecture and Design, RMIT University, Melbourne, \\ Australia
}

\begin{abstract}
The dilemma of the co-existence of humans and industry has been a constant topic of debate among the realms of landscape planning, many times without being clearly articulated as such. This paper examines the conflict through the study of the industrial-residential domain. Natural resources such as water and land are primary reasons of conflict. This paper explores the potential of landscape design to address this conflict. The proposed landscape design strategy green-switch combines the landscape planning concept of "greenways" and the applied ecological engineering concept of "constructed wetland" to address the conflict.
\end{abstract}

Keywords: greenways, urban planning, industrial landscapes, industrialresidential conflict, land and water resource conservation.

\section{Introduction}

The structure of the industrial domain has evolved over the years from a conglomeration of heavy manufacturing industrial estates to light manufacturing industrial parks and most recently to eco-industrial parks - the conglomeration of cleaner production industries engaging in matter and energy exchanges. The industrial domains comprising cleaner industries are increasingly being located within cities, inadvertently becoming a part of the larger geographical and ecological context. This has resulted in conflicting consumption of land and water resources. The planning authorities responsible for planning of these mixed-use zones try to be judicious in allocation of land and water resources to these zones. Mostly, people come to terms with sharing of resources with an industrial domain in view of the perks offered by industries such as employment, 
products for consumption, and also the improved infrastructure in some cases. The loss of ecological values due to rapid replacement of the biophysical environment is overshadowed by other benefits such as jobs and manufactured goods.

The industrial and residential domains exist in various precincts of a city. With this understanding the city can be perceived to exist at a regional scale and the precincts at a local scale. Most of the current ecological landscape design strategies, for example Greenways, are mostly applicable at a regional scale. But if a landscape strategy is to be incorporated within the industrial-residential precinct, it needs to be applicable at a local scale while fitting in the given land footprint and surviving some degree of pollution. The landscape strategy of green-switch satisfies these requirements while simultaneously providing grounds for regaining some of the ecological values lost to densely built, industrial-residential precincts.

Green-switch is further discussed in terms of its theoretical development, structure and design, and the influence on the surrounding ecosystem.

\section{Green-switch}

A switch is a device for opening and closing electrical circuits under normal load conditions. The concept of "switch" is adapted and represented as a "workgate or interconnection" in Odum's [1] energy circuits. Here, the "workgate" depicts work necessary to continue the energy flow through the system. It works as an interconnection of different paths of energy flows and controls the amount of energy flowing through. Inspired by Odum's adaptation of physics to ecology, Wilson and Agnew [2] introduced the concept of the "switch" in vegetation management - as a positive feedback process between species composition and the environment. A vegetation community operates as a vegetation-switch when it modifies the environment to its advantage through a range of abiotic factors such as water supply, $\mathrm{pH}$, light, fire and wind and biotic factors such as the microbial and grazing population.

The proposed landscape strategy of green-switch also adapts the commonly understood notion of "switch" in landscape planning as "switching the flows 'on" or 'off' among landscapes of different types". The green-switch is designed for collecting, diverting or re-distributing the paths of ecological flows; the objective is to facilitate the path of ecological flows by providing alternative flow-paths. It is essentially composed of a single or multiple constructed wetlands. Linear landscapes link multiple constructed wetlands or even the cells within a single constructed wetland when it is designed as such. Thus green-switch is designed to accommodate temporary fluctuations in water storage and treatment capacity, control segregation and integration of pollution treating landscapes with other preserved natural ecosystem and modified landscapes in a contextual ecosystem, and regulate spatial interconnections between industrial and residential domains to facilitate biodiversity flows. Figure 1 presents a conceptual diagram of greenswitch. The figure shows the conceptual inclusion of the green-switch within the industrial premises and at the interface of industrial-residential precincts as the 
component of a larger urbanized context. The possibility of activating the greenswitch at the interface of a urbanized context and a natural ecosystem is also indicated, although not explored through this paper.

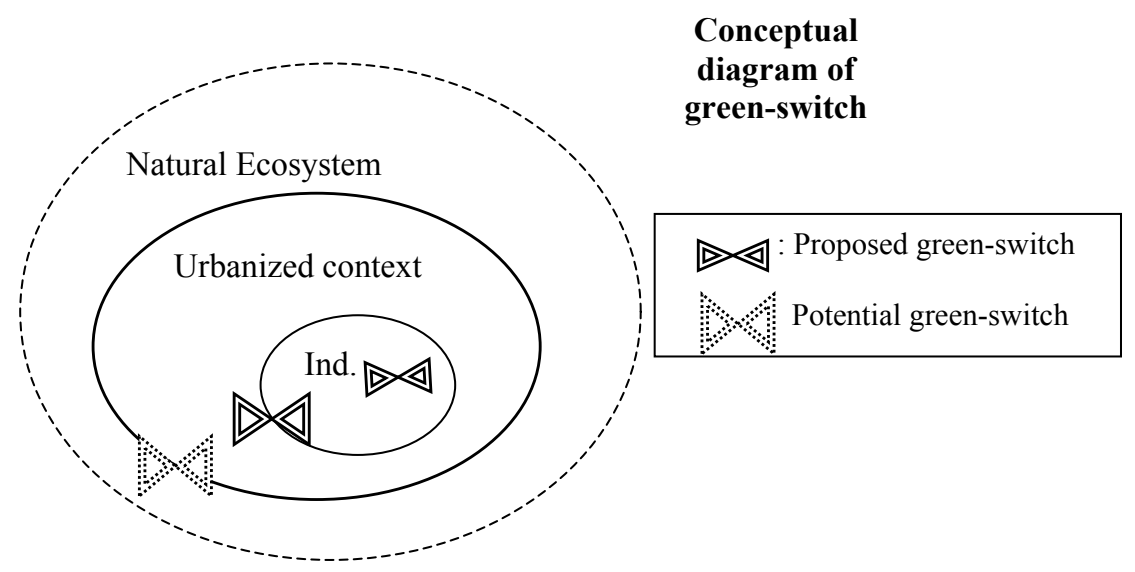

Figure 1: $\quad$ Proposed strategy of green-switch: conceptual diagram.

\subsection{Components of green-switch}

The surface-flow constructed wetland forms a basic module for planning greenswitch since it resembles a naturalistic landscape with an additional ability to treat wastewater. Other measures such as vegetated swales and detention basins could be embedded as the support structure to the constructed wetland. The constructed wetland forms the nodal structure of green-switch and regulates or directs the wastewater flow towards a secondary treatment basin or back to the industrial, human, and biophysical community.

Linear landscapes provide the connections between the constructed wetlands lying within the green-switch or among the group of green-switches. The shape, size and structure of these linear landscapes are determined by a range of objectives. For example, linear landscapes known as 'Greenways' that are developed as biodiversity connectors are guided by the commuting habits and preferred habitat size of that biodiversity. Recent research investigating the potential of linear landscapes of greenway to function as a biodiversity connection has found that narrowing the greenway trail and landscaped surfaces adjacent to the trail, maintenance of a shrub layer and groundcover within the greenway, combined with the protection of greenways contiguous to the landscape with thick canopy cover, increases the diversity and abundance of development-sensitive bird species [3]. The research found that the 50-100 meter wide forested corridors can provide habitat for a variety of bird species, while some species of conservation concern may require corridors wider than 300 meters. 


\section{Making space for incorporating green-switch}

Three rules of making space in the spatially constrained context of a industrialresidential precinct are presented here. These rules are based upon principles and practices of conventional landscape planning and the tenet that land resource is available in a limited quantity at local habitable scales and thus should be judiciously used. The first rule is the "share-ability of land". Land that is open or occupied by the shareable infrastructure such as water supply and drainage-ways is identified as a share-able landscape. The underlying theory of this rule is that the functional value of land, if shared among different zones, will save on the consumption of land, function as a means to spatially integrate different planning zones, and act as a control mechanism for the growth or expansion of each zone. The second rule of "free-ability" draws from the concept of an ecological footprint. The rule implies that the land footprint should be reduced by freeing up the land occupied by the secondary needs of the precinct. The third rule of borrow-ability is about the component taking advantage of its context. The industries can gain from the visual and ecological and recreational benefits of existing gardens and parks lying in its surrounding residential context through strategic site selection, location and development. These rules suggest a way towards judicious consumption of existing resources.

\section{General siting and design considerations for planning green-switch}

The criteria for locating a green-switch are based on the guidelines for planning constructed wetland and greenways [4]. Generally speaking, the green-switch should be located near the common wastewater collection pond, on higher topographical grounds, outside the flow path of water flowing among preserved natural ecosystems and modified ecosystem, and to exert beneficial impact over the water quality, land uses and biodiversity of the surrounding ecosystem. Siting decisions are also influenced by the function attributed to the green-switch such as collection, diversion or re-distribution of water, however one of the components of a constructed wetland of green-switch or one of the green-switch itself is located next to all the common wastewater collection ponds of the industrial-residential precincts to facilitate wastewater treatment. Other factors influencing the siting of green-switch include land conditions, soil chemistry, hydrology/geomorphology, vegetation, presence of endangered species or critical habitat, wildlife, the surrounding landscape, land use/zoning considerations, and potential impacts on safety and health.

The design of the green-switch is determined by the physical characteristics of the constructed wetland and linear landscapes, and by its intended functions such as collection, diversion or distribution. Constructed wetland guidelines advocate avoidance of rectangular basins, rigid structures and straight channels, use of sinuous edges in design configuration, grading the site to use the landform and gravity to the advantage of the project, and designing the margins of the 
constructed treatment wetland system as natural transition zones, including woody vegetated buffer areas around the site.

\section{Discussion}

Green-switch acts as an area for treating or holding the water and its component metals and minerals to be recycled besides facilitating the spatial connection among industrial and residential contexts, thus forming a land loop. Use of selected constructed wetland as spatial workgates controls the undesired mixing of secondary treated water in industrial premises with the tertiary treated recreational water in the surrounding residential context. It acts as a naturalistic valve for directing and distributing the water flows among the industrialresidential precinct. The green-switch thus provides an avenue for conservation of land and water resources.

\section{Conclusion}

Industrial and residential domains have co-existed together for reasons of mutual gains. The residential context provides the industries with raw materials and labor and gains in terms of directly or indirectly usable consumer products and employment. However, the competition for land and water resources persists as an underlying reason of conflict among the two. This is a matter of grave concern as the natural resources are rapidly depleted and the impacts are realized more pronouncedly at the local level. The ecological landscape planning approach offers some indirect answers only, probably because the intensely built urban contexts are not the primary focus of those approaches. The role of greenswitch thus becomes more significant. The potential to treat wastewater and facilitation of biodiversity connections augment the ecological values regained due to increased green-cover in the industrial-residential precincts. The landscape design strategy of green-switch needs to be further explored through multidisciplinary approaches to estimate its true potential.

\section{References}

[1] Odum, E. P., Fundamentals of Ecology, W.B. Saunders Company, Philadelphia, London, Toronto, 1971.

[2] Wilson, J.B. and Agnew, Positive-feedback switches in plant communities, Advanced Ecological Research, 33: 263-336, 16:1-11, 1992.

[3] Hess, G.R. and Moorman, C.E., "Greenways for Wildlife", $<$ www4.ncsu.edu/ grhess/GreenwaysForWildlife>, Retreived in June 2005.

[4] SEPA, Manual: Constructed Wetlands Treatment of Municipal Wastewaters, Office of Research and Development, EPA/625/R-99/010, 1999. 